\section{Laura Otero'}

Belén Sanz'

Teresa Blasco"
Escuela Nacional de Sanidad. Instituto de Salud Carlos III. Ministerio de Ciencia e Innovación. España

" Centro Nacional de Medicina Tropical. Instituto de Salud Carlos III. Ministerio de Ciencia e Innovación. España

\section{Correspondence:}

Laura Otero García

Escuela Nacional de Sanidad

Instituto de Salud Carlos III

C/ Sinesio Delgado, 8

28029 Madrid, España

E-mail: laotero@isciii.es

\section{Early detection of cervical cancer according to the discourses of primary care midwives in Segovia, Spain}

\begin{abstract}
OBJECTIVE: To analyze the discourses of primary care midwives on access to and utilization of the Cervical Cancer Prevention Program.

METHODS: A qualitative study was conducted in an area of low population density with a high proportion of rural population in Segovia, Spain, between 2008 and 2009. Semi-structured interviews were carried out. Ten primary care midwives were interviewed covering the 16 basic health districts of the city. Data analysis was based on grounded theory methodology.
\end{abstract}

RESULTS: Access to and utilization of the Cervical Cancer Prevention Program was associated with attendance to midwife visits, women's experiences with cervical smears and their perception of risk of cervical cancer. Geographic distance to the health center, difficult access to immigrant women who have no health insurance, and being unaware of the program offered are some of the perceived barriers. Social exclusion is also perceived as a barrier of access to and utilization of the program. The recommendation to participate in the program made by the primary care physician was identified as the main facilitator.

CONCLUSIONS: The midwives perceived inequalities in access to and utilization of the Cervical Cancer Prevention Program that are associated to individual characteristics of women, and contextual characteristics such as the geographical environment where they live and Program's infrastructure. There is inequality of access to care of underrepresented groups of women such as immigrant women and those residing in rural areas.

DESCRIPTORS: Uterine Cervical Neoplasms, prevention \& control. Health Services Accessibility. Midwives. Health Knowledge, Attitudes, Practice. Qualitative Research.

\section{INTRODUCTION}

Cervical cancer is the second most prevalent cancer among women worldwide. About 500,000 new cases are reported every year, $80 \%$ of them in underdeveloped countries. There has been a significant decline in cervical cancer in recent decades in Europe, partly due to screening programs. In Spain, cervical cancer rate was 7.6 per 100,000 women in 2002. In the autonomous community of Castile and León the incidence rate of cervical cancer is different in its provinces, ranging from 5 to 13 cases per 100,000 women and the mortality was 2.67 deaths per 100,000 women in 2005. The Cervical Cancer Prevention Program (CCPP) in Castile and León is a planned program targeting sexually active women aged between 20 and 64 designed to provide cervical screenings every three to five years depending on the risk factors associated. 
Social inequalities are associated with unequal cancer prevention. ${ }^{1}$ Studies on access and utilization of cervical cancer prevention programs have been conducted nationwide or region-wide but specific population groups that are quantitatively smaller such as rural residents or immigrants are usually underrepresented. It could be that information obtained from nation-wide studies mask situations of inequality among women living in rural areas; the need to travel great distances to access health care and working hours of services can constitute barriers to access and utilization of CCPP services. On the other hand, immigrant women may have to overcome barriers related to their immigration status, e.g., having no health insurance.

Midwives, who are nurses specialized in obstetrics and gynecology, work in primary care in Spain. In Castile and León they play a connecting role between women users and the CCPP as they are the ones who mainly collect and perform cervical screenings. It is thus crucial to know midwifes' perceptions on the CCPP. The present study aimed to analyze the discourses of primary care midwives on access and utilization of CCPP services.

\section{METHODS}

This study was conducted in the autonomous community of Castile and Leon in the province of Segovia with $64 \%$ of rural population living in 208 rural communities and 17 local districts; $55.6 \%$ of these communities have less than 100 inhabitants. It is estimated that legal immigrant population accounts for $13.1 \%$ of the total population, and immigrants come mainly from Bulgaria, Romania, Morocco, Poland and Colombia.

Segovia is divided into 16 local health districts (LHDs), three of them located in urban areas and 13 in rural areas. Each LHD has a primary health care center where midwife care is provided.

Fieldwork was conducted between February 2008 and November 2009. A qualitative design was used. Semistructured interviews were conducted with midwives who provided primary care. All 16 LHDs were covered as there were six midwives working in more than one LHD, with a total of ten midwives working in the province of Segovia. We used an interview guide to collect information on care activities of midwives, and access and utilization of CCPP services by women users. All participants gave their consent and the interviews were recorded and transcribed. Data analysis was based on grounded theory methodology. Open coding was the first step, where key issues were identified and grouped and labels or codes were assigned to them. Open Code 3.4 was used in this analysis. Axial coding was then used to identify relationships between the codes and categories of analysis were created.
The word midwife is here used to refer to both female and male providers.

All midwifes were informed on the study objectives and gave their verbal consent agreeing to participate in the study, which was recorded. They were assured that their opinions would remain anonymous and confidential. This study is part of a large project that was approved by the Bioethics Committee of Instituto de Salud Carlos III.

\section{ANALYSIS OF RESULTS}

\section{Factors influencing access and utilization of CCPP services}

Attending a primary care visit with a midwife is a form of attracting women to participate in the CCPP.

"Sure, they are attracted because they come in complaining of itching or burning. Before performing a vaginal test you go over their history and then ask: Have you ever done a Pap smear?”

Previous pregnancy is a factor influencing access to CCPP services. Midwifes usually take the opportunity during a postpartum visit to offer these women cervical testing.

“(...) when I provide them care during pregnancy, I schedule a 40-day postpartum visit and then at this visit I schedule another visit for cervical testing."

The midwives studied have found that more women ask about the CCPP because of media information following the approval and dissemination of facts about human papillomavirus (HPV) vaccine.

"People are now more aware of cancer, HPV, vaccines and such."

Women's prior experiences regarding cervical screenings is another influencing factor. The test is performed with the patient in a gynecological position and women may feel embarrassed. Midwives express the importance of making women feel comfortable.

"The whole situation of a cervical screening test, the patient lying down on her back with her legs spread apart and her genitalia exposed, and then someone places a speculum - it is not at all comfortable. They fear being hurt, and I think that sometimes everything goes too fast during these visits."

Midwifes' discourses were varied as to whether women find it more comfortable with female providers. However, they stress the importance of having a trust relationship with a female provider.

"It is an action in which women need to be relaxed and trust a little the person in front of them." 
When women hear of someone diagnosed with cervical cancer in their social environment their risk perception increases as well as their utilization of CCPP services. In contrast, there is a low or no risk perception when they haven't heard of a case of cervical cancer.

“... In these villages women all know about each other's life, and as they haven't health of anyone close dying from cervical cancer so it was not an obsession."

\section{Barriers of access and utilization of CCPP services}

The midwives perceived "problems" to actively attract women users. They compared the CCPP with the breast cancer screening program available and said the latter was able to attract more women. In the CCPP the women are sent the test results and the schedule for the next test. Some of them may miss the follow-up test as sometimes it is scheduled within three to five years.

"This is one of the problems with the cytology program... the mammography program has a clear schedule, they say when a woman have to do the first one and then repeat it. The cytology program sends them a letter following the test saying that 'they have to come back for midwife care within three years.' But they are not reminded of it three years later, or five years later. It's a great weakness of this program."

Rural midwives pointed that women living in communities that provide no health care and who do not drive and/or have a car have difficult access to care. These women have to rely on other people from their social network to attend a midwife care visit because local public transportation is deficient.

"... transportation is a problem for people living in the villages because they have no car to get to the health center... many (women) have to ask their husbands to miss work to take them to the health center, or they have to manage by themselves."

Another barrier to access to care is the status of immigrant. Midwives identified differences in access and utilization of CCPP services between immigrant and resident women, pointing that immigrant women are reluctant to participate and that they have low utilization of services while participating in the program.

“... the immigrant population is more reluctant to have, for example, a cervical screening test. They rarely use the program's services. If they use them for giving birth or for any other reason, we take the opportunity to do a cervical test but then it is not easy to make them come in for follow-up."

When the midwifes were asked why they think immigrant women did not use the services, they pointed socioeconomic status of immigrants, having no health insurance and limited knowledge of the local health system as potential explanatory factors. Many of them said that immigrants living in rural areas come from Romania and Bulgaria and have low socioeconomic condition.

"They use it in their countries, I mean that, for instance, Romania and Bulgaria provide health care, they are not underdeveloped countries. The thing is that they say the immigrants coming here are not middle-condition people but those with the lowest one, and then culturally prevention and care are low..."

Midwives emphasized that the longer these immigrant women are in Spain the more they know about the health system.

When midwives working in rural areas were asked which they thought was a socially excluded group, many said sex workers working in local roads. Their discourses show these women did not use CCPP services.

"It is impossible to attract this group (sex workers). A few years ago we proposed to go and offer our services to them because sex workers are actually a group at risk, as we saw clearly they would not come in for cervical cancer prevention..."

Midwives said they were not aware whether these women used private care services.

Roma women are another group that has been historically socially excluded, and they are mentioned in the discourses of midwives working in urban areas, where most of them live. According to the midwives, they have low participation in the CCPP.

\section{Enabling factors associated with access and utilization of CCPP services}

Midwives believed that health provider's invitation of women to participate in the program was a major enabling factor. Some of them said they actively attracted women by advising them on screening tests offered in their services as opposed to a more passive role of other midwives.

With regard to whether physicians and nurse practitioners provide information and advice to women who are eligible to participate in the CCPP and refer them to midwives, the discourses varied depending on each primary care team. Women are often referred to midwife care when there is an active and effective working relationship between primary care physician and midwives.

"The physicians know exactly when these women should receive midwife care and they refer them to us..."

In other cases there is neither referral nor a relationship between primary care physicians/nurses and midwives. 
"Physicians and nurses in their areas do the uptake. They provide them information or this is what they are supposed to do."

Finally, sending a personal invitation letter to women was identified as an enabling factor for their participation in the program. They said that reminders were sent at times but not consistently.

“... yes, indeed, it depends... there have been times when they send letters and then stop."

\section{DISCUSSION}

Primary care midwives working in the province of Segovia perceived inequalities in access and utilization of CCPP services that are associated with both individual characteristics of women and contextual factors such as geographic area where users live and infrastructure of services. The perceived barriers to access and utilization of services included the need to travel great distances to access health care aggravated by deficient public transportation. Having no health insurance and not knowing the services offered in the CCPP have been identified as barriers for immigrant women. Social exclusion of female sex workers and Roma women was also identified as a barrier to access and utilization of services. Midwives pointed primary care physician advice to participate in the CCPP as an enabling factor as well as sending personal invitation letters to women targeted by the CCPP.

The study findings corroborate other national and international studies that found the following variables associated with participation in programs similar to the CCPP: socioeconomic condition; education level; place of residence; place of origin; ethnicity; age; risk perception; experiences related to cervical screenings; and cultural aspects. ${ }^{1,2,4,6,7-10,12-15}$

In addition to these variables, there is also evidence that women attending more cervical screenings are those who use more health services. ${ }^{11}$ In our study midwives said that women who come in for a visit, especially pregnancy care, are offered to participate in the CCPP. Thus, women who have barriers to access and utilization of health services in general, defined by the literature as women of low socioeconomic condition and immigrant women, ${ }^{4,11}$ are more vulnerable to inequities in access and utilization of prevention programs such as the CCPP.

According to the midwives studied, women's experiences of cervical testing may be associated with their utilization of CCPP services. ${ }^{5,8}$ Negative experiences, i.e., those associated with fear, pain and discomfort, ${ }^{3}$ can make women avoid doing cervical screenings. Midwives believed that to avoid negative experiences there should be a trust relationship between women and their health providers. It is critical to improve communication between midwives and women users.
Increased risk perception of cervical cancer makes women use more CCPP services. Risk perception is increased when women hear of someone diagnosed with cervical cancer in their social environment, and have access to media information. Information about the HPV vaccine in the media and the lack of consensus among health institutions, professionals and authorities have indirectly prompted women to look for information on cervical cancer in the media.

One of the main findings of this study is related to barriers to access and utilization of CCPP services. Midwives mentioned deficient public transportation from rural communities as a barrier to access to midwife care. Rural women usually ask someone in their social network to take them to the nearest primary health care center and this person usually has to request a leave from work. Women living in rural areas require special attention because of potential barriers to access and utilization of CCPP services. ${ }^{9}$

Midwifes believed that immigrant women do not have much access to the CCPP. There is evidence in Spain supporting these perceptions. ${ }^{11}$ Barriers that may be causing inequalities in access and utilization of services are related to having health insurance and knowing the services offered in the CCPP. It is of concern since immigrant women come from developing countries where cervical cancer rates are high. Studies conducted in their countries of origin ${ }^{7,13}$ have shown that low utilization of cervical screening programs is associated with the fact that women have to pay for this service. This is a free public service in Spain' however, we do not know whether those immigrant women who have health insurance are aware of that. Immigrant women living in rural areas may have a more limited social network to overcome the barriers to access and utilization of health services, in particular access to a primary health care center.

As for enabling factors associated with utilization of prevention programs, it was found that health care providers, especially primary care physicians, have a key role in advising women to participate. ${ }^{8}$ Health providers should be aware of their major role in the CCPP, and at the same time develop a good working relationship in the primary care team so that women targeted by the program receive adequate information and advice and can decide on their participation.

We do not know to what extent sex workers living in Segovia participate in the CCPP. Midwives believed that there is underutilization of the CCPP in this group, but we have no data to support this perception.

Also, there is a need to further explore the causes of underutilization of this program among Roma women as identified by midwives. 
Comprehensive health education campaigns can help increase participation in prevention programs. In particular, immigrant women may be a vulnerable group. They should be attracted through targeted health education campaigns rather than only providing informational materials translated into their native

\section{REFERENCES}

1. Arias V, Samuel A. Inequidad y cáncer: una revisión conceptual. Rev Fac Nac Salud Publica. 2009;27(3):341-8

2. Bazargan $M$, Bazargan SH, Farooq M, Baker RS. Correlates of cervical cancer screening among underserved Hispanic and African-American women. Prev Med. 2004;39(3):465-73. DOI:10.1016/j. ypmed.2004.05.003

3. Brito CMS, Nery IS, Torres LC. Sentimentos e expectativas das mulheres acerca da citologia oncótica. Rev Bras Enferm. 2007;60(4):387-90. DOI:10.1590/S0034-71672007000400005

4. Echevarria ES, Carrasquillo O. The roles of citizenship status, acculturation, and health insurance in breast and cervical cancer screening among immigrant women. Med Care. 2006;44(8):788-92. DOI:10.1097/01.mlr.0000215863.24214.41

5. Fylan F. Screening for cervical cancer: a review of women's attitudes, knowledge, and behaviour. $\mathrm{Br}$ J Gen Pract. 1998;48(433):1509-14.

6. Guilfoyle S, Franco R, Goring SS. Exploring older women's approaches to cervical cancer screening. Health Care Women Int. 2007;28(10):930-50. DOI:10.1080/07399330701615358

7. Lucumí-Cuesta DI, Gómez Gutierrez LF. Accesibilidad a los servicios de salud en la práctica de citología reciente de cuello uterino en una zona urbana de Colombia. Rev Esp Salud Publica. 2004;78(3):367-77. DOI:10.1590/S1135-57272004000300006

8. Luengo Matos S, van den Eynde AM. Uso de la citologia de cribado de cérvix y factores relacionados languages at health centers.

In conclusion, it is important to reduce the barriers to access and utilization of CCPP services perceived by midwives so that this prevention program could be more effective for its target women. con el uso de la prueba en España. Aten Primaria. 2004;33(5):229-3. DOI:10.1157/13059170

9. Mauad EC, Nicolau SM, Moreira LF, Haikel Jr RL, Longatto-Filho A, Baracat EC. Adherence to cervical and breast cancer programs is crucial to improving screening performance. Rural Remote Health. 2009;9(3):1241.

10. Parkin DM, Bray F, Ferlay J, Pisani P. Global Cancer Statistics, 2002. CA Cancer J Clin. 2005;55(2):74-108. DOI:10.3322/canjclin.55.2.74

11. Regidor E, Sanz B, Pascual C, Lostao L, Sánchez E, Díaz Olalla J. La utilización de los servicios sanitarios por la población inmigrante en España. Gac Sanit. 2009;23 (Suppl 1):4-11. DOI:10.1016/j.gaceta.2009.01.010

12. Salinas AM, Villarreal E, Garza ME, Fraire JM, López J, Nuñes GM. Quality differences between rural and urban primary care: the case of a cervical cancer screening programme. Int I Qual Health Care. 1998;10(3):235-40. DOI:10.1093/intqhc/10.3.235

13. Todorova I, Baban A, Alexandrova-Karamanova A, Bradley J. Inequalities in cervical cancer screening in Eastern Europe: perspectives from Bulgaria and Romania. Int J Public Health. 2009;54(4):222-32. DOI:10.1007/s00038-009-8040-6

14. Tsu VD, Levin CE. Making the case for cervical cancer prevention: what about equity? Reprod Health Matters. 2008;16(32):104-12. DOI:10.1016/S09688080(08)32411-2

15. Wagner J. Barriers for Hispanic Women in Receiving the Human Papillomavirus Vaccine: A Nursing Challenge. Clin J Oncol Nurs. 2009;13(6):671-5. DOI:10.1188/09.CJON.671-675

Study funded by the Health Research Fund, SEPY Project 1366/08.

The authors declare no conflicts of interest. 